\title{
Acordo ortográfico e a questão do hífen nos compostos
}

Vicente Martins ${ }^{1}$

\section{Resumo}

Este trabalho tem como objetivo de estudo analisar o processo de lematização dos compostos antes e depois do Acordo Ortográfico (2008). Como aporte teórico e metodológico, recorremos às postulações lexicográficas de José-Alvaro Porto Dapena (2002) e à teoria da composição e de sinapsia em Benveniste (2006). Os resultados nos permitiram observar que, por força do princípio composicionalidade, composto como pé de moleque, formado a partir do lexema pé, passou a ser considerado, pelo Dicionário Houaiss (2009), como unidade fraseológica do tipo locução e não mais como uma simples palavra composta por justaposição.

Palavras-chave: Compostos. Sinapsia. Lexicografia. Dicionários. Acordo ortográfico.

\section{Introdução}

As alterações efetuadas pelo Instituto Antônio Houaiss de Lexicografia para a confecção do seu novo Dicionário Houaiss, edição de 2009, adaptada à nova ortografia da língua portuguesa, reduziram não apenas o número de páginas com relação a sua edição de 2001, mas encurtaram, também, o número de entradas ou verbetes. Na edição de 2001, por exemplo, Houaiss contava com 2.922 páginas e o grande volume resultava do número de entradas, que caracteriza sua macroestrutura. Em 2009, o número de páginas caiu para 1.986, transformando muitas entradas da edição anterior em subentradas, agora, com menos informações lexicográficas e registradas na parte horizontal das colunas.

Especulamos, de logo, que a queda do número de páginas, na edição de Houaiss de 2009, ocorreu por conta do novo Acordo Ortográfico: compostos nominais, até então, com entradas próprias, portanto, sendo parte da macroestrutura do dicionário, na nova versão de Houaiss (2009), perderam este status lexicográfico e passaram a ser subentradas durante a lematização. Na edição atualizada do Houaiss (2009), uma palavra como pé de moleque não unicamente perdeu os hífens, mas deixou de oferecer aos consulentes informações como: datação, ano, fonte, análise morfológica, informação gramatical e plural.

\footnotetext{
${ }^{1}$ Mestrado em Educação pela Universidade Federal do Ceará, Brasil (1996). Doutorando - Universidade Federal do Ceará. E-mail: vicente.martins@uol.com.br
} 
Este estudo procura, pois, apontar que o deslocamento do composto nominal pé-demoleque, com hífen, para a categoria de locução nominal pé de moleque, sem hífen, resultou de uma arbitragem de ortógrafos e filólogos do Brasil e de Portugal, e, a rigor, esta prescrição não levou em conta a repercussão lexicográfica na estruturação das novas edições dos dicionários gerais.

O hífen, no âmbito das reformas ortográficas, sempre foi um nó górdio das gramáticas normativas, com pugilatos e controvérsias motivadas por questões fonéticas, fonológicas, morfológicas, etimológicas e, por vezes, semânticas, como no caso das homonímias. Na história da ortografia da língua portuguesa, o hífen cumpriu três funções léxicas: a de ser marca de translineação; a de ser marca de composição lexical e a de ser marca de relações morfossintáticas (GONÇALVES, 2003, p. 573). Graças ao emprego hífen, muitos lexicógrafos resolveram, no primeiro momento, a problemática da grafia de muitas formas linguísticas que, com significados diferentes, tinham a mesma forma gráfica e fônica ou apenas fônica, como no caso dos homônimos. Numa palavra, para o estabelecimento do sentido de uma palavra composta ou de um sintagma, o emprego do hífen se fazia necessário ou, por vezes, determinante para a definição de sua denotação, conotação, designação, sentido ou referência, especialmente no caso das taxionomias ou linguagem técnica ou, ainda, nos casos da idiomaticidade e metaforicidade das unidades fraseológicas, como descrevemos a seguir: a) O sintagma pé de moleque, sem hífen, significa, ao pé da letra, o membro inferior de um garoto da cor negra e 2) pé-de-moleque, com hífen, tem a acepção de tipo de doce. Com o fim do uso do hífen, em pé de moleque, o fenômeno de homonímia superpõe o sintagma ao composto e o sentido literal ao não literal, este, somente dissipado no contexto lingüístico.

Consideramos que houve um equívoco gramatical por parte dos “acordistas” ao abolirem o hífen de pé de moleque, sem levar em conta critérios linguísticos da criação léxica que dele resultou ou, senão, e mais precisamente, não foram observados critérios lexicológicos quando do tratamento dos compostos nominais e das próprias locuções nominais na metalexiografia. Mas, claro, aqui, ao longo do texto não nos posicionamos contra ou a favor do uso do hífen em compostos nominais, como é o caso de pé de moleque, e sim, questionamos da validade de tal medida ortográfica, pensando não apenas na simplificação da indústria editorial ou informática, mas no consulente, especialmente os educandos, no processo de formação escolar e de aquisição de vocabulário da língua.

O certo é que, quando abolimos o hífen em palavras compostas por justaposição e lhes são dadas um tratamento de unidades fraseológicas, imediatamente o lexicógrafo as coloca na 
microestrutura dos dicionários seguindo todos os critérios da lexicografia clássica. Numa última palavra, para tomarmos a lição de Porto Dapena (2002, p.136), quando o composto péde-moleque, antes do Acordo Ortográfico, hifenizado, traz, na sua composição lexical, o hífen, como traço de uma entrada propriamente dita, configura um enunciado ou cabeça do verbete, na macroestrutura do dicionário. Quando pé de moleque perde o hífen, por imperativo do Acordo Ortográfico, passa a ser subentrada e a pertencer à microestrutura do dicionário, não estando mais sujeito à lematização, portanto, a vida da palavra agora está com menos história, com menos etimologia, sem registro de nascimento ou morte da forma lingüística.

Nessas alturas, convém, então, colocarmos algumas novas questões para melhor delinearmos o percurso dessa discussão: com o novo acordo ortográfico, um substantivo composto como pé de moleque, sem hífen, por exemplo, alterou sua classificação morfológica, passando a ser locução nominal ou unidade fraseológica? Qual a repercussão do Acordo Ortográfico na lematização das unidades léxicas formadas por justaposição nos dicionários gerais? Respondemos, de pronto: sim, pé de moleque não é à luz da lexicografia classificada como composto, mas como locução ou unidade fraseológica. Sua lematização é precária e portanto perde seu caráter enciclopédico em se tratando de informação ao consulente.

Após a promulgação do Acordo Ortográfico (2008), no Brasil e nos países lusófonos, observamos, por exemplo, quanto à palavra pé de moleque (um tipo de doce muito conhecido na região nordeste do Brasil), agora, grafada sem hífen, o seguinte em termos de registros lexicográficos: (1) a palavra pé de moleque, sem hífen, portanto, seguindo as prescrições da base XVI do Acordo Ortográfico (1990), lematizada como entrada (lema) na página 964 do Dicionário Escolar da Língua Portuguesa(2008). (2) a palavra pé de moleque, sem hífen, portanto, seguindo as bases do Acordo Ortográfico, lematizada como subentrada na página 1453 do Dicionário Houaiss da Língua Portuguesa (2009). Vale salientar que, no caso de Houaiss, pé de moleque, como subentrada, é classificado como locução e não como substantivo masculino ou palavra composta. (3) na página 631 do Vocabulário Ortográfico da Língua Portuguesa, pé de moleque aparece sem hífen, com status de entrada, seguindo, também, as bases do Acordo Ortográfico e classificada como substantivo masculino.As duas ocorrências, no nosso entendimento, trazem implicações importantes para a lexicografia e análise linguística da unidade léxica pé de moleque, sinteticamente assim: a) como entrada, deve ser, morfologicamente, classificada como substantivo composto e b) como subentrada, deve ser, morfologicamente, classificada como locução nominal. 


\section{Pé de moleque: gramática e lexicologia tradicional}

De há muito, a gramática, especialmente a normativa ou prescritiva, e a lexicologia andam juntas quando nos referimos à estruturação dos dicionários gerais. A lingüística descritiva, por exemplo, define gramática como "estudo objetivo e sistemático dos elementos (fonemas, morfemas, palavras, frases etc.) e dos processos (de formação, construção, flexão e expressão) que constituem e caracterizam o sistema de uma língua”. É também a linguística que define Lexicologia como “ estudo do vocábulo quanto ao seu significado, constituição mórfica e variações flexionais, sua classificação formal ou semântica em relação a outros vocábulos da mesma língua, ou comparados com os de outra língua, em perspectiva sincrônica ou diacrônica”, aproximação de objetivos e objetos, conforme podemos comprovar acima nos verbetes de Houaiss (2009) ao definir os dois termos lingüísticos.

A lexicologia, enquanto teoria da lexicografia, datada de 1858, por Houaiss, é nova no âmbito dos estudos lingüísticos. Assim também o é termo lexicografia, enquanto estudo científico e analítico dos princípios de seleção do vocabulário, de classificação dos vocábulos, de definição e descrição dos significados. Na elaboração dos dicionários gerais, durante muito tempo, a lexicologia foi dependente dos conceitos gramaticais, especialmente os de gramática normativa. Isto ocorria porque a lexicologia era considerada como parte da gramática que estudava as palavras isoladas, consideradas em si. Dizendo de outra forma, a lexicologia se confundia com a própria noção de morfologia que temos hoje.

Uma das gramáticas mais antigas da língua portuguesa, a de Eduardo Carlos Pereira, denominada Gramática Expositiva: curso superior, cuja primeira edição é datada de 1907, portanto, no início do século passado, define lexicologia como parte de gramática que encarada as palavras isoladamente em seus dois elementos fundamentais: em sua parte material que são os sons ou as letras, conforme se trata da palavra falada ou escrita, e em sua idéia ou significação” (PEREIRA, 1957, p. 21). O gramático divide o estudo da lexicologia em duas partes: fonologia e morfologia. Na seção dedicada à sintaxe irregular ou figurada de regência, são estudados os idiotismos léxicos e os idiotismos fraseológicos (p. 258-259). Estas últimas, segundo Eduardo Carlos Pereira, “ refratárias à análise” sintática.

Havia, segundo a lição de Carlos Eduardo Pereira, três maneiras de se efetuar a jusposição das palavras na formação dos compostos: (a) por coordenação ou concordância, em que os elementos componentes são coordenados ou apostos, sendo o determinante ou um adjetivo ou um substantivo aposto, como era (e é ainda), por exemplo, o caso de pontapé 
(golpe com a ponta ou com o peito do pé; chute, formada pela composição de ponta (< latim tadia puncta,ae 'estocada, golpe') + pé cujas formas históricas eram, em 1720 pontapê,; em1789 pontapé); (b) por subordinação ou dependência em que o elemento determinante está subordinado ao elemento determinado, em relação complementar (por exemplo, “pé-degalinha”, conjunto de rugas formadas em torno dos olhos datada de 1899, por Cândido Figueredo) e (c) por meio de locuções ou frases verbais, exemplificada emlocuções do tipo “o lava-pés”, esta, registrada na 6 a edição, datada de 1858, do Diccionario da Língua Portugueza, este publicado, anteriormente, em 1789), de Antonio de Morais Silva, segundo informações do próprio Houaiss (2009).

A influência de concepções do processo de composição, em gramáticas posteriores a de Eduardo Carlos Pereira, pode ser sentida, ainda hoje, em gramáticos ortodoxos e os ditos “menos doutrinários”, isto é, mais modernos e influenciados pelo estruturalismo ou gerativismo como Celso Ferreira da Cunha, em sua Gramática de Base, (1982), que define composição como um processo de formação de palavras que uma nova palavra é formada pela união de dois ou mais radicais: “A palavra composta representa sempre uma idéia única e autônoma, não raro dissociada das noções expressas pelos seus componentes” (CUNHA, 1982, p. 72).Como insistiremos neste artigo, faz e fez bastante diferença quando os ortógrafos, lusitanos e brasileiros, que estabeleceram as bases do Acordo Ortográfico e os lexicógrafos da Academia Brasileira de Letras passaram a classificar pé de moleque como locução nominal e não como composto nominal. Pela definição de locução e pelo próprio exemplário de palavras, entre parênteses, apresentados por Houaiss (2009), pé de moleque se enquadraria como uma locução do tipo substantiva. No Dicionário da Real Academia Espanhola (2009), locução é, também, definida como “combinação fixa de várias palavras que funciona como uma classe especial de palavras”. No caso de espanhol, uma palavra bem próxima da noção que temos de pé de moleque é “ tocino de cielo”, segundo o Dicionário da Real Academia Espanhola um “dulce compuesto de yema de huevo y almíbar cocidos juntos hasta que están bien cuajados”.

\section{Pé de moleque: brasileirismo e cultismo linguístico}

O Dicionário Houaiss (2009) traz as seguintes acepções para a locução nominal pé de moleque: (a) doce consistente feito de açúcar ou rapadura com amendoim torrado, iguaria 
presente na culinária regional do Brasil. (b) bolo feito de mandioca, fubá, coco e açúcar, presente na região nordeste do Brasil e (c) calçamento de rua com pedras irregulares de tamanhos diversos, tipo de pavimentação encontrada em Minas Gerais e no Centro do Oeste do Brasil.

Para nosso estudo, tomaremos, para análise, a primeira acepção de pé de moleque: “doce consistente feito de açúcar ou rapadura com amendoim torrado. Expressões como “doce consistente feito de açúcar” e "rapadura com amendoim torrado" nos sugerem ser o pé de moleque uma iguaria de fabricação caseira, tradicional e extremamente popular no Brasil. O doce pé de moleque é bastante relacionado às culturas caipira e açoriana, isto é, tem uma origem na culinária de origem caipira (brasileirismo) e açoriana (lusitanismo).

No âmbito da gramática tradicional e da lingüística estrutural, o composto nominal ou a locução nominal pé de moleque, com e sem hífen, antes e depois do Acordo Ortográfico, é tipicamente português, portanto, vernacular. Diríamos, a rigor, que pé de moleque, grafado, antes do Acordo Ortográfico e depois do Acordo Ortográfico, traz traços lexicológicos do plebeísmo, brasileirismo e populismo.

Pé de moleque, por ter mais de uma acepção, o ideal de uma reforma ortográfica mais ampla e com base nos fundamentos da lingüística contemporânea, especialmente a Lexicologia e Semântica, é que levasse em conta que um composto desta natureza morfológica tem, pelo menos, três acepções de acordo com cada contexto, o que, naturalmente, justificaria as duas grafias com e sem hífen para cada sentido: (a) doce consistente feito de açúcar ou rapadura com amendoim torrado, registro no vocabulário da culinária regional do Brasil (grafado com hífen); (b) bolo feito de mandioca, fubá, coco e açúcar, registro no vocabulário da culinária do Nordeste do Brasil (grafado com hífen); e (c) calçamento de rua com pedras irregulares de tamanhos diversos, registro no vocabulário regional de Minas Gerais, Centro-Oeste do Brasil (nesse caso, o ideal é que fosse grafado sem hífen). Mas, nessas alturas, poderíamos levantar uma nova pergunta: como, realmente, arbitrar o uso do hífen na composição do composto como pé de moleque levando em conta suas diversas acepções ou motivações semânticas?

Com a datação em 1899, pé de moleque, até 2008, era grafado com hífen, indicando claramente seu processo de composição lexical, isto é, sua gênese de criação lexical. Há aspectos extralingüísticos também a considerar na criação lexical da palavra pé de moleque, com ou sem hífen, uma vez que é uma forma lingüística própria do dialeto social da população com pouca instrução e que não faz parte do uso culto formal. Não se trata de uma palavra estigmatizada por um preconceito lingüístico, mas ao se ler ou ouvir a palavra pé de 
moleque sabemos que estamos diante de uma palavra de feição popular. Um rápido levantamento de outras unidades lexicais, relacionadas a doces, oriundas da cultura popular, confirmarão nossa postulação da natureza popular a ser atribuída ao composto, senão vejamos: baba-de-moça, beiços-de-moça, beijo-de-estudante, bolo-de-beata, bolo-de-estouro, bolo-de-sogra, busca marido, engorda marido, espera marido, orelhas-de-burro, pão-de-ló, pudim come-e-cala, puxa-puxa, quero-mais.

Para melhor compreensão do composto pé de moleque e de outros compostas formados a partir do lexema pé, como “pé de burro”, “pé de cabra”, “pé de cachorro”, recorremos à hipótese Sapir-Whorf. Por esta hipótese, postularíamos que, para o caso de pé de moleque, a língua portuguesa traz uma infra-estrutura (pé+de+moleque) que determinam a natureza das culturas brasileira (caipira) e lusitana(açoriana), isto é, os elementos da palavra pé de moleque, de motivação icônica (a forma do doce evoca a perna de um garoto da raça negra), induzem a forma das representações do sujeito falante e até mesmo as determinam profundamente.

A palavra pé de moleque, enquanto subentrada, nos atuais dicionários gerais, do lexema pé, exerce o papel de determinado, contendo a idéia geral do composto e se caracteriza, em se tratando de contexto lingüístico, como um elemento que precede o determinante. E o que justificaria pé ser entrada e não subentrada? Cremos que o fato de ser uma palavra de origem latina. Ao contrário da palavra pé de moleque, de origem vulgar e com características formais (e rudimentares) do português brasileiro, em geral, marcado por construções lexicais hifenizadas.

Por fim, diríamos que antes e depois do Acordo Ortográfico(2008), as palavras, formadas a partir de pé, por via erudita ou formadas a partir do modelo da composição latina, preservaram sua autonomia de entrada própria no processo de lematização dos dicionários. Enfim, a este respeito, podemos supor que uma das explicações para esse fenômeno lexicográfico estaria na idéia de que tudo aquilo que a língua portuguesa traz por herança latina, por meio do acusativo, na lexicologia, ainda com feição conservadora, sugere a linguagem escorreita, correta, sem estrangeirismos na pronúncia ou na lexicalização. É, em substância, a força do cultismo lingüístico, em que o componente lingüístico lexical ou morfológico é introduzido ou mantido nos dicionários, seguindo o rigor da inspiração purista na seleção das entradas dos dicionários gerais das línguas modernas ou neolatinas, como é o caso do português, espanhol ou italiano. 


\section{Pé de moleque: cognição e lexicologia}

A questão da composição é um das categorias centrais da lingüística cognitiva. Alias, quando o lexicógrafo transforma, por exemplo, no processo de lematização, o composto nominal pé-de-moleque, com hífen e com entrada própria, em locução nominal pé de moleque, sem hífen,portanto, fazendo a conversão de composto justaposto para uma unidade fraseológica do tipo locução, procede assim com base no princípio da composicionalidade ou na análise composicional do léxico, tomando como referência os portes da Semântica e da Linguística Cognitiva.

Quando dizemos que pé de moleque é um tipo regional de doce ou bolo ou, ainda um tipo de calçamento, distanciando seu significado do sentido literal que os seus componentes sugerem (pé X moleque), este significado baseia-se no principio da não composicionalidade, caracterizado, como bem define Frank Neveu (2008), “por uma opacidade semântica que varia principalmente em função do grau de cristalização das expressões e pelas restrições sintáticas” (p. 74). Como se trata de um composto, diríamos que essas restrições a que Neveu faz referência são, na verdade, princípios da ordem ou sequencialidade do sintagma nominal.

A lingüista Nicole Delbecque (2008) afirma que, na estrutura interna dos compostos nominais, por exemplo, há uma estreita dependência do significado de base das diferentes classes de palavras que se combinam. Uma palavra como pé de moleque, nesse caso, denotaria algo de caráter estável, por oposição, por exemplo, numa frase como fazer fincapé, que nos sugere "manter-se firme em resolução, em opinião; fincar-se, obstinar-se, teimar”, que evocaria coisa menos estável.

Com base ainda nas postulações cognitivistas de Nicole Delbecque, postularíamos que, no grupo dos compostos nominais, entre os quais podemos encontrar como palavras como pé de moleque ou pé de negro, ambos, iguarias, há toda uma espécie de relações semânticas entre os dois componentes, indicando o princípio de iconicidade observado no estabelecimento de "uma certa semelhança entre a forma do enunciado e aquilo que ele representa” (DELBECQUE, 2008, p. 26).

Esse princípio de iconicidade se manifesta ainda, do ponto de vista cognitivo, através de três outros princípios de estruturação da linguagem: (a) princípio da ordem linear, onde observamos, no caso de pé de moleque, com ou sem hífen, a disposição linear dos componentes no interior do vocábulo (pé + de + moleque); (b) princípio da distância, em 
que pé de moleque, com ou sem hífen, pode ser flexionado pés de moleque, a partir do que entendemos como sendo um elo conceitual. Nesse caso, se o plural fosse pé de moleques ou pés de moleques, estaríamos, a rigor falando de perna de garotos negros ou pernas de garotos negros e não do doce e, por último, (c) princípio de quantidade, em que, para o caso de pé de moleque, com ou sem hífen, tem três acepções: doce, bolo e calçamento isto é, uma grande quantidade de forma é associada a uma grande qualidade de significado. No levantamento de lexemas feito a partir entrada de pé, em Houaiss (2009), encontramos, pelo menos, 23 acepções (por exemplo, em domínios relacionados com anatomia botânica, construção, geometria, artes gráficas, metrologia, versificação, decoração, anatomia zoológica), mas quando diante da lista de locuções ou unidades fraseológicas o número de ocorrência salta para, pelo menos, 118 expressões fixas. Vejamos os quadros comparativos de entradas e subentradas antes e depois do Acordo Ortográfico:

Quadro 1 - 71 compostos com pé, hifenizados, antes do acordo ortográfico

\begin{tabular}{|c|c|}
\hline Pé-de-alferes & Pé-de-negro \\
\hline PE-de-altar & Pé-de-oiro \\
\hline Pé-de-amigo & Pé-de-ouro \\
\hline Pé-de-anjo & Pé-de-ouvido \\
\hline Pé-de-atleta & Pé-de-papagaio \\
\hline Pé-de-banco & Pé-de-parede \\
\hline Pé-de-bezerro & Pé-de-pato \\
\hline Pé-de-bode & Pé-de-pau \\
\hline Pé-de-boi & PE-de-pavão \\
\hline Pé-de-briga & Pé-de-peia \\
\hline Pé-de-burrinho & Pé-de-perdiz \\
\hline Pé-de-burro & Pé-de-poeira \\
\hline Pé-de-cachorro & Pé-de-pomba \\
\hline Pé-de-cana & Pé-de-pombo \\
\hline Pé-de-carneiro & Pé-de-rabo \\
\hline Pé-de-carneiro & Pé-de-rola \\
\hline Pé-de-cavalo & Pé-de-serrense \\
\hline Pé-de-chinelo & Pé-de-valsa \\
\hline Pé-de-chumbo & Pé-de-vento \\
\hline pé-de-elefante & Pé-direito \\
\hline Pé-de-escada & Pé-duro \\
\hline Pé-de-galinha & Pê-efe \\
\hline Pé-de-galinha-verdadeiro & Pê-efe \\
\hline Pé-de-galo & Pê-eme \\
\hline Pé-de-gancho & Pé-encarnado \\
\hline Pé-de-garrafa & Pé-fresco \\
\hline Pé-de-gato & Pé-frio \\
\hline pé-de-lebre & Pé-lavado \\
\hline Pé-de-lobo & Pé-leve \\
\hline pé-de-lugar & pé-na-cova \\
\hline Pé-de-macaco & Pé-no-chão \\
\hline Pé-de-meia & Pé-quebrado \\
\hline Pé-de-mesa & Pé-quente \\
\hline Pé-de-moleque & Pé-rachado \\
\hline
\end{tabular}




\begin{tabular}{|l|l|}
\hline Pé-de-mosca & Pé-rapado \\
\hline Pés-de-cabra & \\
\hline
\end{tabular}

Fonte: Houaiss, 2001

Quadro 2 - Compostos com pé, hifenizados, depois do acordo ortográfico

\begin{tabular}{|l|l|}
\hline & pé-atrás \\
& pé-cascudo \\
pé-d'água & pé-de-bezerro \\
& pé-de-boi \\
& pé-de-cabra \\
& pé-de-chumbo \\
& pé-de-galinha \\
& pé-de-galo \\
& pé-de-gato \\
& pé-de-meia \\
& pé-de-pau \\
& pé-direito \\
& pé-encarnado \\
& pé-frio \\
\hline
\end{tabular}

Fonte, Houaiss, 2009

Quadro 3 - Unidades fraseológicas com pé, sem hífen, depois do acordo ortográfico

\begin{tabular}{|c|c|c|c|}
\hline 1. & a pé & 2. & pé cavo \\
\hline 3. & a pé de & 4. & pé chato \\
\hline 5. & a pé de galo & 6. & pé de alferes \\
\hline 7. & a pé firme ou quedo & 8. & pé de altar \\
\hline 9. & abrir no pé & 10. & pé de amigo \\
\hline 11. & ao pé da letra & 12. & pé de anjo \\
\hline 13. & ao pé de & 14. & pé de árvore \\
\hline 15. & ao pé do ouvido & 16. & pé de arvoredo \\
\hline 17. & apertar o pé & 18. & pé de atleta \\
\hline 19. & bater (o) pé & 20. & pé de banco \\
\hline 21. & botar o pé na fôrma & 22. & pé de bode \\
\hline 23. & botar o pé no mundo & 24. & pé de boi \\
\hline 25. & cair de pé & 26. & pé de briga \\
\hline 27. & com o pé atrás & 28. & pé de burro \\
\hline 29. & com o pé direito & 30. & pé de cabra \\
\hline 31. & com o pé esquerdo & 32. & pé de cachorro \\
\hline 33. & com o pé no estribo & 34. & pé de cana \\
\hline 35. & com pés de lã & 36. & pé de carneiro \\
\hline 37. & com pés de ladrão & 38. & pé de chinelo \\
\hline 39. & com um pé nas costas & 40. & pé de chumbo \\
\hline 41. & dar no pé & 42. & pé de escada \\
\hline 43. & dar pé & 44. & pé de galinha \\
\hline 45. & de pé & 46. & pé de gancho \\
\hline 47. & de pé atrás & 48. & pé de garrafa \\
\hline 49. & de pé quebrado & 50. & pé de mato \\
\hline 51. & de quatro pés & 52. & pé de mesa \\
\hline 53. & dez pés em quadrão & 54. & pé de pato \\
\hline 55. & do pé para a mão & 56. & pé de pau \\
\hline 57. & em pé & 58. & pé de pavão \\
\hline 59. & em pé de guerra & 60. & pé de peia \\
\hline 61. & em pé de igualdade & 62. & pé de poeira \\
\hline 63. & em pés de lã & 64. & pé de rabo \\
\hline 65. & encher o pé & 66. & pé de valsa \\
\hline
\end{tabular}




\begin{tabular}{|c|c|c|c|}
\hline 67. & encostado ao pé da embaúba & 68. & pé de vento \\
\hline 69. & estar com o pé na cova & 70. & pé equino \\
\hline 71. & fazer pé atrás & 72. & pé na cova \\
\hline 73. & fazer pé de alferes a & 74. & pé na tábua \\
\hline 75. & ficar no pé de (alguém) & 76. & pé no chão \\
\hline 77. & ir aos pés & 78. & pé torto \\
\hline 79. & ir e vir num pé só & 80. & pé valgo \\
\hline 81. & ir num pé e vir no outro & 82. & pé varo \\
\hline 83. & ir num pé e voltar no outro & 84. & pegar no pé \\
\hline 85. & ir num pé só & 86. & pegar pelo pé \\
\hline 87. & jurar de pés juntos & 88. & perder (o) pé \\
\hline 89. & lamber os pés de & 90. & pés de lebre \\
\hline 91. & largar do pé de & 92. & pés e pelos \\
\hline 93. & meter o pé (em) & 94. & pés no chão \\
\hline 95. & meter o pé no atoleiro & 96. & pisar no pé \\
\hline 97. & meter o pé no lodo & 98. & $\begin{array}{l}\begin{array}{l}\text { sofrer que só pé de } \\
\text { cego }\end{array} \\
\end{array}$ \\
\hline 99. & meter o pé no mundo & 100. & $\begin{array}{l}\text { ter os pés fincados na } \\
\text { terra }\end{array}$ \\
\hline 101. & meter os pés em & 102. & ter os pés na terra \\
\hline 103. & meter os pés pelas mãos & 104. & ter os pés no chão \\
\hline 105. & não arredar pé & 106. & ter pé \\
\hline 107. & não chegar aos pés de & 108. & ter um pé na cova \\
\hline 109. & negar a pés juntos & 110. & tirar o pé da lama \\
\hline 111. & passar o pé adiante da mão & 112. & tirar o pé do lodo \\
\hline 113. & pé ambulacrário & 114. & tomar pé \\
\hline 115. & pé ante pé & 116. & tomar pé em ou de \\
\hline 117. & pé calcâneo & 118. & um pé lá, outro cá \\
\hline
\end{tabular}

Fonte: Houaiss, 2009

\section{Pé de moleque: de composto à locução nominal}

Para uma discussão lingüística ainda mais apurada sobre o destino lexicográfico da palavra pé de moleque, postularíamos, com base em Émile Benveniste (2006), que, por meio da sinapsia, houve, por força das novas bases do Acordo Ortográfico, a transformação do composto pé-de-moleque, nominal, justaposto e hifenizado, em locução nominal, grafado sem hífen. Para Benveniste, palavras compostas como pé de moleque, pé de negro, pé de cachorro, pé de cabra, entre tantas, presentes na língua portuguesa, caracterizam-se por sua polilexicalidade não unida no plano formal, o que nos leva a supor que a supressão do hífen em palavras acima referidas, não interferiu na sua idiomaticidade, cristalização e na sua nãocomposicionalidade semântica.

Como vimos, anteriormente, a palavra pé de moleque, com ou sem hífen, respectivamente, antes ou depois do Acordo Ortográfico (2008), é classificada pelos gramáticos como um composto nominal, formado por dois radicais, por meio da justaposição. 
O normativismo vê, na composição de pé de moleque, uma “união, em uma só palavra com significado independente, de palavras distintas que conservam, cada uma, sua integridade fonética”. Para os ortógrafos do Acordo Ortográfico (2008), lexicógrafos da Academia Brasileira de Letras e os dicionaristas do Instituto Houaiss de Lexicografia, ao contrário dos gramáticos, pé de moleque, depois de obedecidas as bases do Acordo na formação das palavras, é, com a perda do hífen, uma unidade fraseológica do tipo locução nominal.

Não é, todavia, uma questão do hífen nos compostos não é fácil de ser solucionada ou esclarecida. Até aqui temos feito um esforço para dirimir esta dicotomia: composto X locução, sem que isso, claro, afetemos as acepções tradicionamente à atribuídas à palavra pé de moleque. Certo é que pé de moleque é, na longa tradição das gramáticas prescrtivas, uma palavra classificada como composto nominal. Hoje, classificá-la como locução nominal não traz implicações semânticas, mas traz discrepância ou divergência na estruturação da macro e microestrutras dos dicionários gerais, especialmente em se tratando da perda de informações culturais e enciclopédicas sobre o verbete.

Explico melhor: Como composto nominal, antes do Acordo Ortográfico, pé-demoleque, com o diacrítico hífen, usado para unir os elementos de palavras compostas, tinha entrada própria no Dicionário de Houaiss (2001). Dizer que tinha entrada própria significa que pé de moleque abria um verbete nos dicionários gerais, verdadeiramente, uma unidade léxica ou cabeça. Isso acontecia com outras dezenas de palavras, conforme demonstraremos em quadro mais adiante. Portanto, pé-de-moleque se enquadrava, no dicionário de Houaiss, como entrada pertencente a uma estrutura ordenada de todas as entradas (nominata). Pé-demoleque, enfim, fazia parte de um item na relação de entradas de Houaiss.

Depois do Acordo Ortográfico, pé de moleque, sem hífen, passa a ser subentrada da cabeça pé, conforme podemos atestar em Houaiss (2009). Em que ou quem, então, se respaldar para a mudança classificação de pé de moleque e de outras com a mesma forma de composição lexical? Como tentamos até aqui mostrar, com o novo Acordo Ortográfico, a palavra pé de moleque passou a fazer parte da microestrutura do dicionário, entendida aqui como item pertencente a estrutura interna da unidade básica de referência (o verbete pé).

O processo de lematização de pé-de-moleque, com hífen, pertencente à macroestrutura de Houaiss à forma pé de moleque, sem hífen, pertencente à microestrutura do referido dicionário, apaga uma série de informações, conforme podemos observar nos quadros comparativos a seguir: 
Quadro 4 - O lexema pé-de-moleque, com hífen, antes do acordo ortográfico

\begin{tabular}{|c|c|}
\hline \multicolumn{2}{|r|}{ ENTRADA } \\
\hline & $\begin{array}{c}\text { Pé-de-moleque } \\
\text { (HOUAISS: 2001, p.2163) }\end{array}$ \\
\hline & $\begin{array}{l}\text { 1. Datação: } \\
\text { 1.1. Ano: } 1899 \\
\text { 1.2. Fonte: CF } \\
\text { 2. Acepções: } \\
\text { 2.1. Morfologia: substantivo masculino } \\
\text { 2.1.1. Rubrica: culinária. } \\
\text { 2.1.1.1. Regionalismo: } \\
\text { 2.1.1.1.1. } \quad \text { Brasil: doce consistente feito de açúcar ou rapadura } \\
\text { com amendoim torrado. } \\
\text { 2.1.1.1.1.1. Nordeste do Brasil: bolo feito de mandioca, fubá, coco e } \\
\text { açúcar } \\
\text { 2.1.1.2. Angola: amendoim torrado, descascado e triturado posto em } \\
\text { calda de açúcar temperada com erva-doce até o ponto de cortar; feito em } \\
\text { torrões (colocados em cartuchos cônicos) ou placas triangulares ou } \\
\text { retangulares } \\
\text { 2.2. Regionalismo: } \\
\text { 2.2.1. Minas Gerais, Centro-Oeste do Brasil. } \\
\text { com pedras irregulares de tamanhos diversos } \\
\text { 3. Gramática } \\
\text { 3.1. Plural: pés-de-moleque }\end{array}$ \\
\hline
\end{tabular}
Fonte: Houaiss, 2001 
Quadro 5 - O lexema pé de moleque, sem hífen, depois do acordo ortográfico

\begin{tabular}{|c|c|}
\hline \multicolumn{2}{|c|}{ ENTRADA } \\
\hline \multicolumn{2}{|c|}{$\begin{array}{l}\text { PÉ: substantivo masculino: 1.Rubrica: anatomia humana.extremidade do membro inferior abaixo da } \\
\text { articulação do tornozelo e terminada pelos artelhos, assentada por completo no chão, e que permite a } \\
\text { postura vertical e o andar. Datação: século XIII. Etimologia: lat. pes,pèdis 'pé' }\end{array}$} \\
\hline \multicolumn{2}{|c|}{ SUBENTRADA } \\
\hline \multicolumn{2}{|r|}{$\begin{array}{c}\text { Pé de moleque } \\
\text { (HOUAISS: 2009, p. 1453) }\end{array}$} \\
\hline & 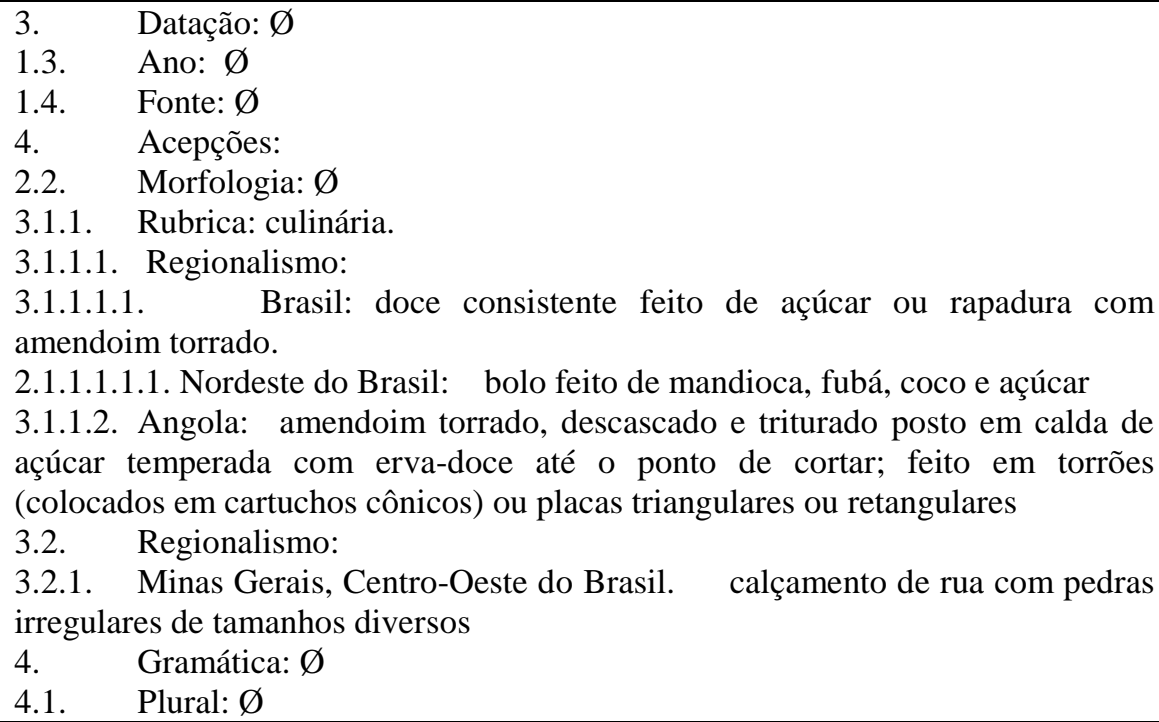 \\
\hline
\end{tabular}

Fonte: Houaiss, 2009

\section{Pé de moleque: o fenômeno da catacrese}

Do ponto de vista estilístico ou retórico, o composto pé de moleque pode ser analisado, semanticamente, como fenômeno de catacrese, com ou sem hífen. Houaiss (2009) define catacrese como um tipo de "metáfora já absorvida no uso comum da língua, de emprego tão corrente que não é mais tomada como tal, e que serve para suprir a falta de uma palavra específica que designe determinada coisa”. Aqui, mais uma vez, voltamos a questão da composicionalidade semântica: o processo de formação do composto indica três itens: pé + de + moleque.

O primeiro item, o substantivo pé, nos remete à anatomia humana: “extremidade do membro inferior abaixo da articulação do tornozelo e terminada pelos artelhos, assentada por completo no chão, e que permite a postura vertical e o andar”. O segundo item, a preposição de, cuja função essencial é a de relacionar palavras por subordinação e expressar os sentidos”. No caso específico de pé de moleque, a preposição “de” expressa semelhança, isto é, uma parecença (ou analogia) do formato do doce com o formato do pé de um moleque. Finalmente, o terceiro item, moleque, a partir de acepções do regionalismo brasileiro, o 
sentido de menino novo, de raça negra ou mista; garoto de pouca idade ou criado à solta; menino de rua ou ainda, garoto travesso.

O que justificaria então apontarmos, na composicionalidade de pé de moleque, um fenômeno catacrésico? Respondemos que foi determinante para o fenômeno de catacrese o fato extralingüístico de darmos, metaforicamente, ao composto pé de moleque um novo sentido, por meio de uma translação, em que designa um tipo de doce, consistente e feito de açúcar com amendoim torrado, com configuração física semelhante a um membro inferior(pé) de um garoto de pele negra ou mestiça. Em substância, o fenômeno de catacrese em pé de moleque indica, claramente, que o sentido que damos a este composto não pertence ao sistema da língua, mas está associado, semântica ou metaforicamente, à aplicação deste na produção e na compreensão do composto no que tange ao sujeito ou à situação, e ao conhecimento de mundo que os falantes do Nordeste do Brasil, Minas Gerais e Centro-Oeste do Brasil compartilham entre si.

\section{Considerações finais}

Com este estudo, chegamos à conclusão de que o Acordo Ortográfico, promulgado, em 2008, pelo governo brasileiro e ratificado pelos países lusófonos, trouxe importantes repercussões na elaboração dos dicionários gerais. Como composto nominal, observamos que as principais características de pé de moleque eram: (a) Realização gráfica: ligação com um separador (um espaço ou um hífen; (b) Contém dois ou mais morfemas léxicos (unidade significativa); (c) Variação (aleatória) em um mesmo estágio da língua (sincronia); (d) Formação resultante da polilexicalidade (sinapsia); (e) Cristalização; (f) Neutralização das propriedades combinatórias das unidades constituintes e (g) Não composicionalidade do sentido.

Registramos, depois da aplicação do Acordo Ortográfico (2008) à formação léxica dos compostos, as seguintes características fraseológicas, como, por exemplo, o caso de pé de moleque: (a) Unidade polilexical do tipo sintagmático; (b) Constituintes não objeto de uma atualização separada; (c) Anunciam um conceito autônomo; (d) Bloqueio da propriedades combinatórias e transformacionais e (e) Não-composicionalidade de sentido.

A partir do conceito de composição em Benveniste (2006), verificamos que, pelo processo de sinapsia, a palavra pé de moleque e outras congêneres, antes e depois do Acordo Ortográfico passaram a apresentar os seguintes traços sinápticos: (a) a persistência do traço 
sintagmático verificado na ligação entre os componentes (pé+de-moleque); (b) A permanência, depois da reforma ortográfica, do emprego de juntores para esse efeito, sobretudo as preposições DE e A ; (c) A permanência, por princípio de natureza cognitiva, da ordem determinado + determinante dos membros (pé/ de+moleque, onde pé é determinado e de+moleque, o determinante); (d) Pé, por força do processo de sinapsia, caracteriza-se por sua forma lexical plena, e a livre escolha de qualquer substantivo ou adjetivo (pé de cabra,em pé de guerra, ir num pé e voltar no outro etc); (e) Como subentrada, pé de moleque não traz artigo antes do determinante (pé de moleque); (f) Possibilidade de expansão de um ou outro membro (pés de moleque ou os pés de moleque) e (g) Caráter único e constante do significado: doce, bolo ou calçamento. Pé de moleque, assim, não é, depois do Acordo Ortográfico, um composto, mas uma locução ou uma sinapsia.

\section{Referências}

ACADEMIA BRASILEIRA DE LETRAS. Vocabulário ortográfico da língua portuguesa. 5. ed. São Paulo : Global, 2009.

BECHARA, Evanildo. Moderna gramática portuguesa. Rio de Janeiro: Lucerna, 1999.

BENVENISTE, Émile. Problemas de lingüística geral II. 2. ed. Campinas: Pontes, 2006.

CAMARA JUNIOR, J. Mattoso. Dicionário de linguística e gramática. 21. ed. Petrópolis: Vozes, 2000.

CUNHA, Celso Ferreira da. Gramática de base. 3. ed. Rio de Janeiro: FENAME, 1982.

DELBECQUE, Nicole. Linguística cognitiva: compreender como funciona a linguagem. Lisboa: Instituto Piaget, 2008.

DICIONÁRIO escolar da língua portuguesa (com a nova ortografia da língua portuguesa). Academia Brasileiro de Letras. 2. ed. São Paulo: CEN, 2008. [Com a nova ortografia da língua portuguesa]

DUBOIS, Jean et ali. (Org.). Dicionário de linguística. São Paulo: Cultrix, 1993.

FERREIRA, Aurelio Buarque de Holanda. Novo dicionário da língua. 2. ed. Rio de Janeiro: Nova Fronteira, 1986.

GONÇALVES, Maria Filomena. As ideias ortográficas em Portugal: de Madureira Feijó a Gonçalves Viana (1734-1911). Lisboa: Fundação Calouste Gulbenkian, 2003. 
HOUAISS, Antônio ; VILLAR, Mauro de Salles. Dicionário Houaiss da língua portuguesa Elaboração do Instituto Antônio Houaiss de Lexicografia e Banco de Dados da Língua Portuguesa. Rio de Janeiro: Objetiva, 2009. [com a nova ortografia da língua portuguesa]

HOUAISS, Antônio ; VILLAR, Mauro de Salles. Dicionário Houaiss da língua portuguesa. Elaboração do Instituto Antônio Houaiss de Lexicografia e Banco de Dados da Língua Portuguesa. Rio de Janeiro: Objetiva, 2001.

NEVEU, Franck. Dicionário de ciências da linguagem. Petrópolis : Vozes, 2008.

PEREIRA, Eduardo Carlos. Gramática expositiva : curso superior. 102. ed. São Paulo: CEN, 1957.

PORTO DAPENA, José-Alvaro. Manual de técnica lexicográfica. Madrid: Arco/libros, 2002.

TRASK, R. L. Dicionário de linguagem e lingüística. São Paulo: Contexto, 2006. 